\title{
Construction of a Chimeric Series of Bacillus Cyclomaltodextrin Glucanotransferases and Analysis of the Thermal Stabilities and $\mathrm{pH}$ Optima of the Enzymes
}

\author{
By TAKAHIRO KANEKO, ${ }^{*}$ KI-BANG SONG, $\dagger$ TETSUO HAMAMOTO, \\ TOSHIAKI KUDO AND KOKI HORIKOSHI \\ Laboratory of Applied Bacteriology, The Riken Institute, Wako-shi, Saitama-ken 351-01, Japan
}

(Received 21 February 1989; revised 23 August 1989; accepted 4 September 1989)

\begin{abstract}
The cyclomaltodextrin glucanotransferase (CGTase, EC 2.4.1.19) gene from the alkalophilic Bacillus sp. strain no. 17-1 was cloned in Escherichia coli. The cloned CGTase gene consisted of a single open reading frame which would encode a polypeptide of 713 amino acids, and the first 27 amino acid residues comprised a signal peptide. The nucleotide sequence and the amino acid sequence of this CGTase (CGTase 17-1) gene had strong homology with those of the CGTase (CGTase 38-2) gene previously cloned in our laboratory from the alkalophilic Bacillus sp. strain no. 38-2, although the enzymic properties of the CGTase 17-1 were distinct from those of the CGTase 38-2. To analyse those enzymic properties further, we constructed 12 chimeric CGTases using three restriction nuclease sites and compared the enzymic properties of the chimeric CGTases. The N-terminal part of the enzyme was important for heat stability, and the $\mathrm{pH}$-activity profile was influenced by both the $\mathrm{N}$ - and the C-terminal parts. A third segment was less important for enzymic properties.
\end{abstract}

\section{INTRODUCTION}

Cyclomaltodextrin glucanotransferase (EC 2.4.1.19, CGTase) produces a mixture of alpha-, beta- and gamma-cyclodextrins from starch or related carbohydrates. We have reported the enzymic properties of a CGTase produced by the alkalophilic Bacillus sp. strain no. 38-2 (Nakamura \& Horikoshi, 1976), and analysed the nucleotide sequence of the CGTase (CGTase 38-2) gene from this strain (Kaneko et al., 1988). We have also isolated a CGTase (CGTase 17-1) from alkalophilic Bacillus sp. strain no. 17-1 (Yamamoto et al., 1972). Here we report the cloning of the CGTase gene from strain 17-1. We compare the gene and amino acid sequences of CGTase 38-2 and CGTase 17-1, and their properties, and describe the construction of chimeric enzymes using the CGTase genes from the two strains. Through analysis of the properties of the chimeric enzymes, the role of various enzyme segments in the structure and function of CGTase 38-2 and CGTase 17-1 proteins were examined.

\section{METHODS}

Bacterial strains and media. Alkalophilic Bacillus sp. strain no. 17-1 (ATCC 31007) was isolated in our laboratory from soil (Yamamoto et al., 1972). Escherichia coli $\mathrm{K} 12$ strain $\mathrm{HB} 101$ ( $\mathrm{F}^{-}$hsd-20 recA13 ara-14 proA2 lacY1 galK2 $r p s L 20 x y l-5 \mathrm{mtl}-1$ supE44), was used as a host strain (Messing et al., 1981). The alkaline medium (pH 10) contained $1 \%(\mathrm{w} / \mathrm{v})$ soluble starch, $0.5 \%$ yeast extract, $0.5 \%$ polypeptone, $0.1 \% \mathrm{~K}_{2} \mathrm{HPO}_{4}, 0.02 \% \mathrm{MgSO}_{4} .7 \mathrm{H}_{2} \mathrm{O}$, and (sterilized separately) $1 \% \mathrm{Na}_{2} \mathrm{CO}_{3}$. LB-starch medium (Maniatis et al., 1982) containing $0.2 \%$ soluble starch was used for growth of $E$. coli.

DNA isolation and cloning. Bacillus sp. 17-1 was grown aerobically at $37^{\circ} \mathrm{C}$ in the alkaline medium described above. Chromosomal DNA was isolated by the method of Saito \& Miura (1963). Plasmid DNA was purified by the method of Bolivar et al. (1977). A boiling method was used for rapid isolation of plasmids (Davis $e t$ al., 1980).

$\dagger$ Present address: Genetic Engineering Research Center, KAIST, PO Box 131, Dong Dae Mun, Seoul, Korea.

Abbreviation: CGTase, cyclomaltodextrin glucanotransferase.

The nucleotide sequence data reported in this paper have been submitted to GenBank and have been assigned the accession number M28053. 
The cloning strategy was as follows. After complete digestion with PstI, plasmid pUC19 DNA (1 $\mu \mathrm{g})$ and chromosomal DNA $(3 \mu \mathrm{g})$ were mixed and ligated with T4 DNA ligase. The ligated DNA was used to transform E. coli HB101 by the method of Lederberg \& Cohen (1974). The transformants were plated on the LB-starch plates, containing $50 \mu \mathrm{g}$ ampicillin $\mathrm{ml}^{-1}$. CGTase activity was detected as starch hydrolytic activity on LB-starch agar plates using $\mathrm{I}_{2} / \mathrm{KI}$ indicator solution.

Amino acid sequence and amino acid composition. The CGTase enzyme was purified as described by Nakamura \& Horikoshi (1976). The N-terminal amino acid sequence was determined by the method of Edman \& Henschen (1975) using a Protein/Peptide Sequencer model 477A, and the PTH analyser model 120A system (Applied Biosystems). Amino acid composition was determined as described by Spackman et al. (1958) with a Hitachi amino acid analyser, model 835, after hydrolysis with $6 \mathrm{M}-\mathrm{HCl}$ (Moore \& Stein, 1963).

DNA sequencing. Sequencing was done using the dideoxy chain-termination reaction (Sanger et al., 1977) by the exonuclease deletion method (Henikoff, 1984) with pUC18 and pUC19.

Construction of the chimeric enzymes. Plasmid pUCP1, containing the CGTase gene from alkalophilic Bacillus sp. 17-1, was obtained in the present study (see Results and Fig. 1). The $3.6 \mathrm{~kb}$ HindIII fragment containing the CGTase gene from alkalophilic Bacillus sp. 38-2 (Kaneko et al., 1988) was inserted into pUC19, the orientation of the CGTase gene being the same as that of pUCP1. The resulting plasmid (CGTase ${ }^{+}, \mathrm{Ap}^{\mathrm{r}}, 6 \cdot 1 \mathrm{~kb}$ ) was designated pCS100.

Using three aligned restriction nuclease sites, the $N d e I, E c o 47 I I I$ and $B a l$ sites in both the CGTase 17-1 gene (pUCP1) and the CGTase 38-2 gene (pCS100), 12 chimeric CGTase genes were constructed (see Figs 5 and 6).

Plasmid pCGT1 contained a chimeric gene (SUUU). ' $S$ ' and ' $U$ ' represent regions from CGTase 38-2 and CGTase 17-1, respectively. For example, 'SUUU' indicates the chimeric enzyme in which the N-terminal segment was derived from CGTase 38-2 gene and the second, third, and fourth segments were derived from CGTase 17-1. Plasmid pCGT1 was constructed by ligation of a $3.6 \mathrm{~kb}$ NdeI(I)-NdeI(II) fragment [N-terminal segment (1S) of the CGTase 38-2 gene and most of plasmid pUC19] of pCS100 and a 2.3 kb NdeI(2)-NdeI(3) fragment [the second, third and fourth segments (2U, 3U, 4U) of the CGTase 17-1 gene] of pUCP1.

Plasmid pCGT2 (SSUU) was constructed by ligation of a $4.7 \mathrm{~kb}$ Eco47III(II)-Eco47III(I) fragment (1S, 2S) of pCS100 and a $3.0 \mathrm{~kb}$ Eco47III(2)-SmaI fragment (3U, 4U) of pUCP1. Plasmid pCGT3(SSSU) was constructed by

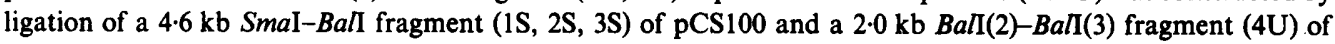

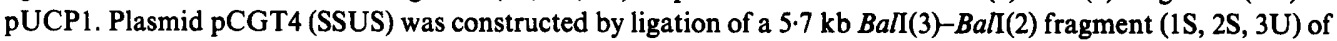
pCGT2 and a $1.5 \mathrm{~kb}$ Ball-SmaI fragment (4S) of pCS100. Plasmid pCGT5 (USSS) was constructed by ligation of a $4.5 \mathrm{~kb}$ NdeI(1)-NdeI(2) fragment (1U) of pUCP1 and $2.5 \mathrm{~kb} N d e I(I I)-N d e I(I)$ fragment (2S, 3S, 4S) of pCS100. Plasmid pCGT6 (USSU) was constructed by ligation of a $5.5 \mathrm{~kb}$ SmaI-Ball fragment (1U, 2S, 3S) of pCGT5 and a $2.0 \mathrm{~kb}$ Ball(2)-BalI(3) fragment (4U) of pUCP1. Plasmid pCGT7 (USUU) was constructed by ligation of a $4.5 \mathrm{~kb}$ $N d e I(1)-N d e I(2)$ fragment (1U) of pUCP1 and a $2 \cdot 3 \mathrm{~kb} N d e I(I I)-N d e I(3)$ fragment (2S, 3U, 4U) of pCGT2. Plasmid pCGT8 (UUUS) was constructed by ligation of a $5.5 \mathrm{~kb} S \mathrm{SmaI}-\mathrm{BaII}(2)$ fragment (1U, 2U, 3U, partially digested with $B a l \mathrm{I}$ ) of pUCP1 and a $1.5 \mathrm{~kb} B a l \mathrm{I}-S m a I$ fragment (4S) of pCS100. Plasmid pCGT9 (UUSS) was constructed by ligation of a $5.2 \mathrm{~kb} S \mathrm{maI}-E \operatorname{co47III}(2)$ fragment (1U, 2U, partially digested with Eco47III) of pUCP1 and a $1.4 \mathrm{~kb}$ Eco47III(I)-Eco47III(II) fragment (3S, 4S) of pCS100. Plasmid pCGT10 (USUS) was

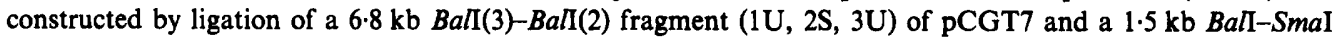
fragment (4S) of pCS100. Plasmid pCGT11 (SUUS) was constructed by ligation of a $3.6 \mathrm{~kb}$ NdeI(I)-NdeI(II) fragment (1S) of pCS100 and a $2.5 \mathrm{~kb} N \operatorname{Nd} \mathrm{I}(2)-N d e \mathrm{I}(\mathrm{I})$ fragment (2U, 3U, 4S) of pCGT8. Plasmid pCGT12 (SUSS) was constructed by ligation of a $3.6 \mathrm{~kb} N d e \mathrm{I}(\mathrm{I})-N d e \mathrm{I}$ (II) fragment (1S) of pCS100 and a $2 \cdot 1 \mathrm{~kb} N d e \mathrm{I}(2)-$ NdeI(I) fragment (2S, 3S, 4S) of pCGT9.

CGTase assay. CGTase activity was measured as dextrinizing power using amylose as a substrate, according to the method of Fuwa (1954), with a slight modification. In the standard assay, the reaction mixture, containing $50 \mu$ l enzyme solution (suitably diluted with distilled water) and $0.3 \mathrm{ml} 0.2 \%$ amylose in $10 \mathrm{~mm}$-phosphate buffer (pH 6.0), was incubated at $60^{\circ} \mathrm{C}$ for $10 \mathrm{~min}$. The reaction was stopped with $0.5 \mathrm{ml}$ of $1 \mathrm{M}$-acetic acid and $0.5 \mathrm{ml}$ $0.02 \% \mathrm{I}_{2} / 0.2 \% \mathrm{KI}$ solution. Distilled water was added to make up a final volume of $10 \mathrm{ml}$, and absorbance at $700 \mathrm{~nm}$ was measured. One unit of enzyme was defined as the amount of enzyme which produced a $10 \%$ reduction in the intensity of blue colour of the amylose-iodine complex per minute under the conditions described.

Enzymes and chemicals. RNAase, lysozyme, and ampicillin (Ap) were purchased from Sigma. Restriction endonucleases, DNA polymerase I and T4 ligase were obtained from Toyobo, Osaka, Japan. The M13 sequence kit and exonuclease deletion kit were from Takara Syuzo, Kyoto, Japan. All other chemicals used were of reagent grade.

\section{RESULTS AND DISCUSSION}

Cloning and sequencing of the CGTase gene from alkalophilic Bacillus sp. strain no. 17-1

Cloning in E. coli. About $4 \times 10^{4}$ colonies of the transformants were screened; one transformant showed amylolytic activity on LB-starch plates using the $I_{2} / K I$ indicator, and 


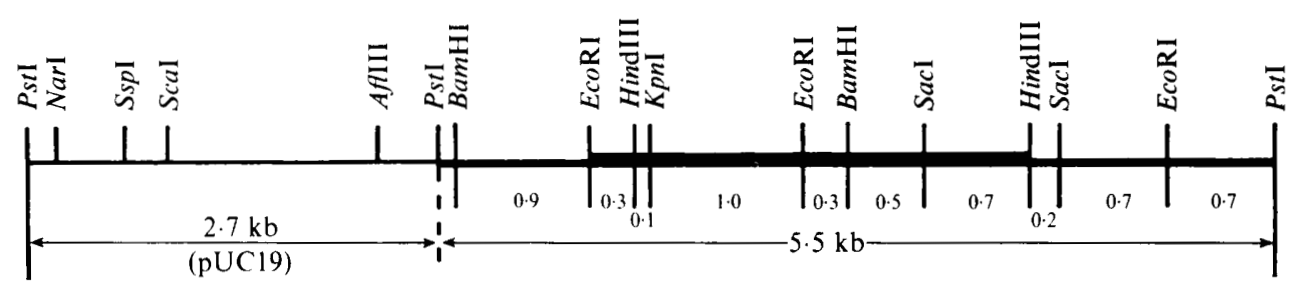

Fig. 1. Restriction map of plasmid pUCP1. Restriction sites are indicated, and their coordinates given in $\mathrm{kb}$. The medium and thick lines indicate the cloned fragment from alkalophilic Bacillus sp. 17-1. The thick line indicates the fragment containing the CGTase gene.
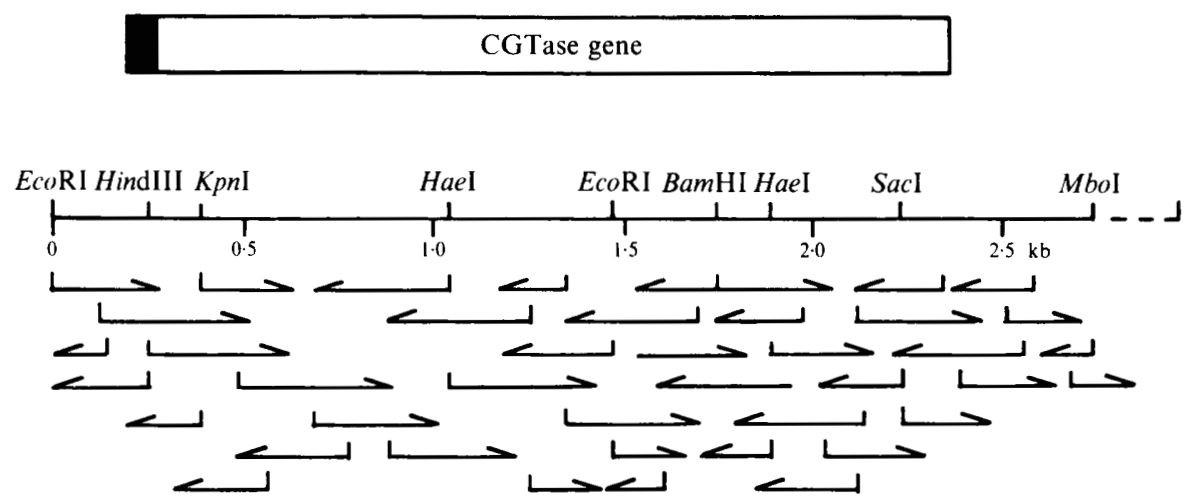

Fig. 2. Strategy for sequencing the CGTase gene of alkalophilic Bacillus sp. 17-1. A detailed restriction map of the EcoRI-MboI region of pUCP1 encoding the CGTase gene and the sequencing strategy are shown. The arrows below the line represent the direction and extent of sequence determinations done by the dideoxy chain-termination method of Sanger et al. (1977). Extra $\mathrm{MboI}$ sites were located at positions 249, 306, 667, 676, 739, 1036, 1192, 1338, 1505, 1725, 1834, 2022 and 2203 in Fig. 3. The $M$ boI site at position 2422 (Fig. 3) is shown here.

showed CGTase activity using a paper chromatography method (Kobayashi et al., 1984). The plasmid thus obtained was designated as pUCP1; it contained a $5.5 \mathrm{~kb}$ insert of Bacillus sp. 17-1 DNA. A restriction map of the $5.5 \mathrm{~kb}$ insert of pUCP1 is shown in Fig. 1.

To determine the origin of the DNA inserted in pUC19, the $5.5 \mathrm{~kb}$ insert DNA was biotinylated (Langer et al., 1981), and hybridized to PstI-digested chromosomal DNA of Bacillus sp. 17-1 and E. coli HB101, immobilized on a nitrocellulose sheet (Southern, 1975). The biotinylated segment hybridized to a $5.5 \mathrm{~kb}$ chromosomal DNA segment of Bacillus sp. 17-1 identical in length to that contained in pUCP1. No complementary sequences were detected in E. coli chromosomal or plasmid DNA fragments.

DNA sequence. We determined the DNA sequence of a $2.9 \mathrm{~kb} E c o \mathrm{RI}-M b o \mathrm{I}$ region of pUCP1 (Fig. 2). The nucleotide sequence and the deduced amino acid sequence are shown in Fig. 3. Analysis of the sequence showed that there was a single open reading frame of $2139 \mathrm{bp}$ which could encode a polypeptide of 713 amino acids. The SD sequence AGGAGG, which is highly complementary to the $3^{\prime}$ end of $B$. subtilis 16S rRNA (Murray \& Rabinowitz, 1982), was observed $6 \mathrm{bp}$ upstream of the initiation codon.

Determination of amino acid composition and $\mathrm{N}$-terminal amino acid sequence. The $\mathrm{N}$-terminal amino acid sequence of CGTase 17-1 was determined up to the 17th residue to be $\mathrm{NH}_{2}$-Ala-ProAsp-Thr-Ser-Val-Ser-Asn-Lys-Gln-Asn-Phe-Ser-Thr-Asp-Val-Ile. This amino acid sequence was identical to that deduced from the DNA sequence starting at nucleotide position 82 in Fig. 3. The initial 27 amino acid residues (residues -27 to -1 ) seemed to represent a signal 
ECORI

GAAT $\bar{T}$ GCTTTCATTTACAATATTGTTGAAATCAAACACTCGC

ATAATTTAAGGGCCATGCATTCCGTCACCGCACACCCGGTATGGAACAACCCCGGTTTCTCTTCAGGAGATGCCGGGGTTTTTTGTTGCC CTATATTTCGTACAGGAGGTGATTCCCCGCAGCTTCGGTTTGATCATTGAACCAACCCCCATTCTATAACTGCTACATAGGAGGAATACG $\begin{array}{llllllll}10 & 20 & 30 & 40 & 50 & 60 & \text { HindIII70 } & 80 \downarrow \\ \text { (SD) } 90\end{array}$

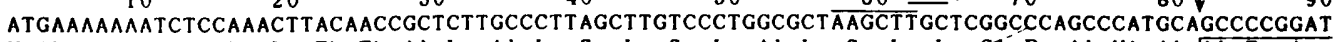

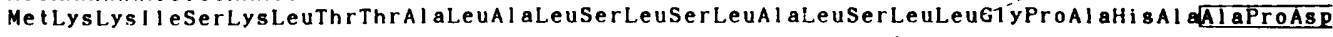
$(-27)$
100
110
120
130
140
150
160
170

(1) 180

ACCTCGGT TTCCAACAAGCAAAATTTCAGCACGGATGTCATTTATCAAATCTTTACGGACCGTT TCTCCGACGGCAATCCTGCCAACAAC

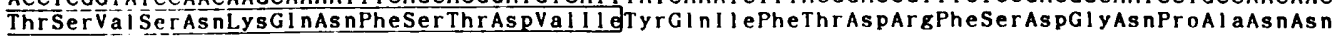

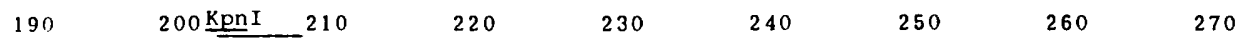

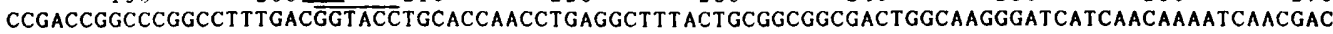

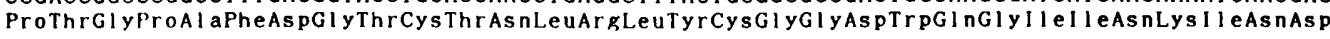

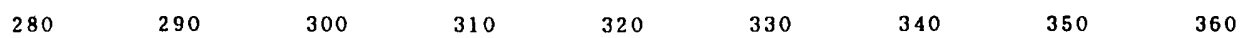
GGCTACCTGACCGGCATGGGCGT TACCGCCATCTGGATCTCCCAGCCGGTCGAGAACATCT ACAGCGTCATCAATTAT TCCGGCGTGAAT

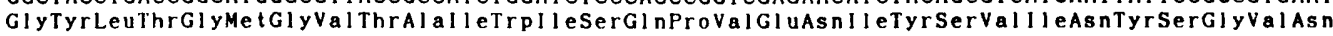
370
380
390
400
410
420
430
440
450 AACACCGCATACCACGGCTATTGGGCTAGAGACT TCAAGAAAACG AACCCGGCTTACGGCACGATTGCCGATTTCCAGAATCTCATCGCT

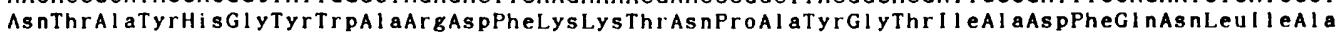

$\begin{array}{lllllrrr}460 & 470 & 480 & 490 & 500 & 510 & 520 & 530\end{array}$
GCCGCCCATGCCAAGAACATCAAAGTCATCATCGACT TCGCACCGAACCACACGTCT CCCGCT TCCT TGGACCAGCCGTCGT TTGCGGAG

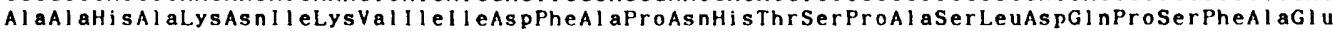

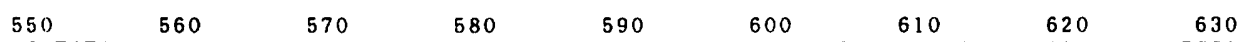
AACGGCAAGCTGTACAACAACGGCAGGGACGAAGGCGGATACACGAACGATACGCACAATTTATTCCATCATAACGGGGGCACCGATTTC AsnGI yLysLeUTyrAsnAsnGl yArgAspGIUGI yGI yTyrThrAsnAspThrHisAsnLeuPheHisHisAsnGl yGI yThrAspPhe
640
650
660
670
680
$690 \quad 700$
710
720

TCGACGACCGAGAACGGGATTTACAAAAACCTGT ACGATCTTGCCGATCTGAACCACAACAACAGCACAGTGGATACCTACCTGAAGGAT

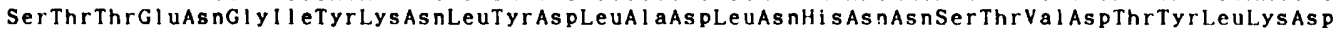

$\begin{array}{ccccccc}730 & 740 & 750 & 760 & 770 & 780 & 790\end{array}$ GCCATTAAAATGTGGCTCGATCTGGGCATTGACGGCATTCGAATGGACGCGGT AAAACATATGCCGTTCGGCTGGCAGAAGAGCTTCATG

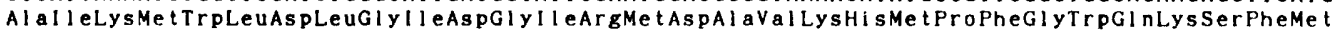

$\begin{array}{llllllll}820 & 830 & 840 & 850 & 860 & 870 & 880 & 890\end{array}$ GCCACCGTCAACAATTACAAGCCGGTCT TCACCTTCGGCGAATGGTTCCTCGGGGTAAACGAAGTGAGTGCCGAGAATCATAAGTTCGCC AlaThrVal AsnAsnTyrLysProVal PheThrPheGl yGluTrpPheLeuGl yValAsngluValSerAlaGluAsnHisLys PheAla

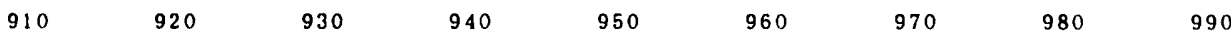
AACGTTTCCGGCATGAGCCTGCTGGACT TCCGCT TCGCGCAGAAGGT TCGCCAGGTATTCAAGGACAACACCGACAATATGT ACGGACTG

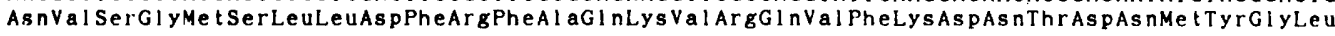

$$
\begin{array}{llllllll}
1000 & 1010 & 1020 & 1030 & 1040 & 1050 & 1060 & 1070
\end{array}
$$

AAATCCATGCT AGAGGGCTCTGCGACCGATT ACGCGCAGATGGAGGATCAGGTCACGTTCATCGAT AACCACGACATGGAACGTTTCCAC

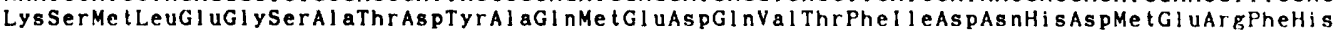

$\begin{array}{llllllll}1090 & 1100 & 1110 & 1120 & 1130 & 1140 & 1150 & 1160\end{array}$ AAT AACAGCGCCAACCGCCGGAAGCTGGAGCAAGCGCTCGCCTTCACGTTAACTTCCCGCGGCGTGCCAGCCATCTATTATGGAACCGAG

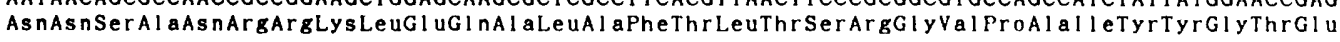
1180
1190
1200
1210 ECORI 1220
1230
1240
1250
1260 CAATACATGTCCGGCGGGAACGATCCCGACAACCGGGCTC GAATTCCTTCTTTCTCTACCACGACTACGGCTTATCAGGTCAGTAAAAAG GInTyrMe tSerGIYGI yAs nAspProAspAsnArgAlaArgI leProSerPheSerThrThrThrThrAlaTyrGInVaISerLysLys $\begin{array}{llllllll}1270 & 1280 & 1290 & 1300 & 1310 & 1320 & 1330 & 1340\end{array}$ CTGGCGCCTCTGCGTAAATCCAATCCGGCCATCGCTTATGGGACGACGCAGGAGCGCTGGATAAACAACGATGTGTTGATCTATGAGCGC

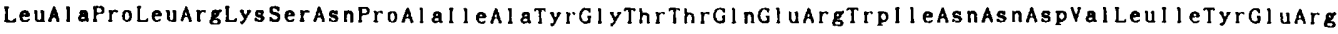

$\begin{array}{llllllll}1360 & 1370 & 1380 & 1390 & 1400 & 1410 & 1420 & 1430\end{array}$ AAGTTCGGCAACAACGT AGCCGTCATCGCCGTCAACCGCAACGTGAACACGTCGGCCTCCATTACGGGACTGGTAACCTCACTGCCGGCC

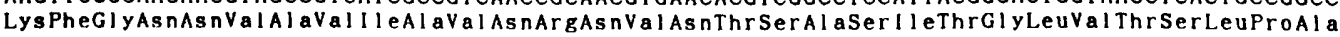

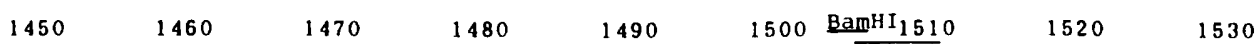
GGCAGCTACACCGACGTGCTGGGCGGCCTCT TGAACGGTAACAATTTGACCGTCGGCTCCGGCGGATCCGCTTCCATCTTCACGCTGGCA GI ySerTyrThrAspValLeuGI yGI yLeuLeuAsnGI yAsnAsnLeuThrValGI ySerGI yGI ySerAlaSerI lePheThrLeuAla

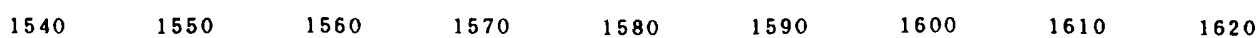

GCGGGCGGT ACGGCCGTGTGGCAATACACCACGGCCGTGACTGCGCCAACCATCGGGCACGTAGGACCGATGATGGCCAAACCAGGCGCA AlaGlyGI YThrAlaValTrpGInTyrThrThrAlaValThrAlaProThrl leGiyHisValgl yProMetMetAlaLysProGlyAla $\begin{array}{llllllll}1630 & 1640 & 1650 & 1660 & 1670 & 1680 & 1690 & 1700\end{array}$ GCCGTCACCATTGACGGCCGCGGTTTCGGTGCAACCAAAGGCACGGT AT ACTTCGGCACGACGGCAGTTACCGGCGCTAAT ATTACGGCT AlaValThr I I AspGI yArgGI yPheGI yAlaThrLysGlyThrVaITyrPheGI yThrThrAlaValThrGI yAlaAsnI leThrAla 
$\begin{array}{lllllllll}1720 & 1730 & 1740 & 1750 & 1760 & 1770 & 1780 & 1790 & 1800\end{array}$ TGGGAAGACACGCAGATCAAAGTGAAAATCCCTGCCGTTGCCGGAGGCGTATACAATATCAAAATCGCCAACAGTGCCGGAACCTCAAGC

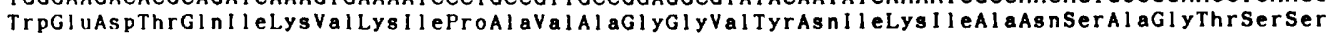
$\begin{array}{lllllllll}1810 & 1820 & 1830 & 1840 & 1850 & 1860 & 1870 & 1880 & 1890\end{array}$ AATGTGCATGACAACTTCGAAGTGCTGAGCGGGGATCAGGTCAGCGTGCGCTTTGTGGTGAACAACGCCACCACCGCGCTCGGCCAGAAC

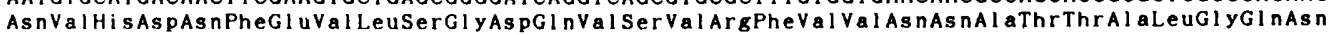

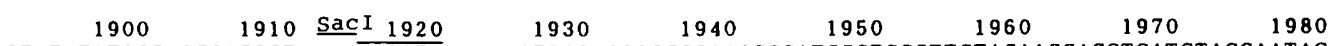
GTATATCTGGCAGGCAGCGT AAGCGAGCTCGGCAACTGGGACCCGGCCAAAGCCATCGGTCCGT TGT ACAACCAGGTCATCTACCAATAC Val TyrLeuAlaGl ySerVal SerGI uLeuGl yAsnTrpAspProAlaLysAlaI leGI yProLeuTyrAsnGInVaII leTyrGInTyr

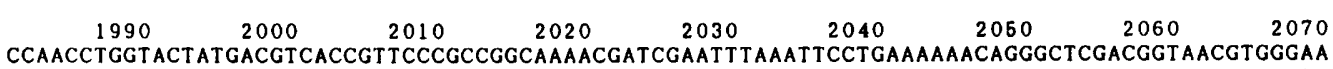
ProThrTrpTyrTyrAspValThrVal ProAlaGlyLysThrlleGluPhelys PheLeuLysLysinglySerThrValThrTrpGlu

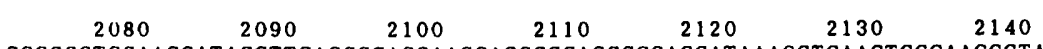

GGCGGCTCGAACCATACCTTCACCGCACCAACGAGCGGCACGGCCACCATAAACGTGAACTGGCAACCGTAAGTTCAAGAACGACTAGCT Gl yGl ySerAsnHisThrPheThrAl aProThrSerGlyThrAlaThrIleAsnVal AsnTrpGlnPro*** (686)

TCTGCCGAAGAACGGCCCCTAAACAAAACCAGCTCCGGATATGATCCCGGAGCTGGTTTTGTTCATGCAGGTCATAATTCCAGTAGCAAT

AGCCCGTTACGCGAAGCATCTCACAGT TCCTCTGAACTGCATGAGCGATTCCCAAAGAGAGAGCGTGCTCAGCAGGCAGTAACTCAGCAT

TCCTCTGCATTGCATGAGCGATTCCCAAAGgGAGAGCGTCTCAACAAGT AGTGACTCAGCAAGCAGACGgGaCAaCtCAACGATC

Fig. 3. Nucleotide sequence of the CGTase gene from alkalophilic Bacillus sp. 17-1. The DNA sequence is given in the direction $5^{\prime}$ to $3^{\prime}$, numbered from nucleotide 1 at the putative initiation site. The proposed ribosome-binding site (Shine-Dalgarno, SD) is underlined with a dotted line. The predicted amino acid sequence is given below the DNA sequence. The deduced position of processing of the signal peptide is indicated by an arrow. The boxed amino acids have been determined by automated Edman sequencing of the purified CGTase.

Table 1. Amino acid composition predicted from the DNA nucleotide sequence of the CGTase from alkalophilic Bacillus sp. 17-1 compared with that determined from the purified enzyme

\begin{tabular}{|c|c|c|c|c|c|c|c|}
\hline \multirow[b]{2}{*}{$\begin{array}{l}\text { Amino } \\
\text { acid }\end{array}$} & \multicolumn{2}{|c|}{$\begin{array}{c}\text { From DNA } \\
\text { sequence }\end{array}$} & \multirow{2}{*}{$\begin{array}{c}\text { Amino acid } \\
\text { analysis } \\
(\mathrm{mol} \%)\end{array}$} & \multirow[b]{2}{*}{$\begin{array}{c}\text { Amino } \\
\text { acid }\end{array}$} & \multicolumn{2}{|c|}{$\begin{array}{c}\text { From DNA } \\
\text { sequence }\end{array}$} & \multirow{2}{*}{$\begin{array}{c}\text { Amino acid } \\
\text { analysis } \\
(\mathrm{mol} \%)\end{array}$} \\
\hline & No. & $\widehat{\mathrm{Mol} \%}$ & & & No. & Mol\% & \\
\hline Lys & 31 & $4 \cdot 5$ & $5 \cdot 2$ & Gly & 65 & 9.6 & $10 \cdot 1$ \\
\hline $\mathrm{His}$ & 13 & 1.9 & $2 \cdot 1$ & Ala & 62 & $9 \cdot 1$ & $10 \cdot 1$ \\
\hline Arg & 19 & $2 \cdot 7$ & $3 \cdot 1$ & Cys & 2 & 0.3 & - \\
\hline Trp & 13 & 1.9 & $0 \cdot 2$ & Val & 48 & 6.9 & $7 \cdot 6$ \\
\hline Asx * & 101 & 14.7 & 14.7 & Met & 13 & 1.9 & 1.0 \\
\hline Thr & 66 & 9.5 & 8.9 & Ile & 38 & $5 \cdot 6$ & $5 \cdot 6$ \\
\hline Ser & 42 & $6 \cdot 1$ & $5 \cdot 9$ & Leu & 39 & 5.6 & $6 \cdot 3$ \\
\hline Glx* & 43 & $6 \cdot 3$ & 6.0 & Tyr & 32 & $4 \cdot 7$ & $4 \cdot 8$ \\
\hline Pro & 27 & 3.9 & 4.8 & Phe & 32 & 4.6 & 4.9 \\
\hline
\end{tabular}

- , Not detected.

* Asx represents Asp and Asn; Glx represents Glu and Gln.

peptide which was removed during the secretion process. Thus, the mature CGTase comprised 686 amino acids and had an $M_{\mathrm{r}}$ of 74140 . The amino acid composition of CGTase 17-1 was calculated from the deduced amino acid sequence and compared with the composition of purified CGTase. Molar ratios obtained by these analyses were closely consistent (Table 1).

Comparison of the nucleotide sequences and deduced amino acid sequences of the CGTase genes of alkalophilic Bacillus sp. strain no. 17-1 and strain no. 38-2. We previously cloned and analysed the nucleotide sequence of the CGTase gene of Bacillus sp. 38-2 (Kaneko et al., 1988). Fig. 4 shows the nucleotide sequence and amino acid sequence alignment between the CGTase 17-1 and 
T A L A S

$S$

A S $\quad$ G $\quad$ A

ATGAAAAAAATCTCCAAACTTACAACCGCTCTTGCCCTTAGCTTGTCCCTGGCGCTAAGCTTGCTCGGCCCAGCCCATGCAGCCCCGGAT

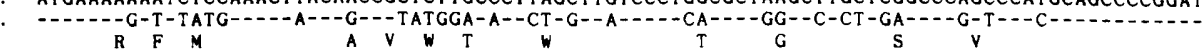

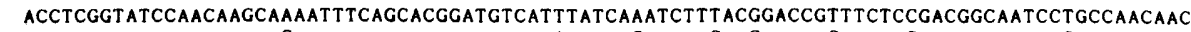

2.

$T$

1. CCGACCGGCCCGGCCTTTGACGGT ACCTGCACCAACCTGAGGCTTTACTGCGGCGGCGACTGGCAAGGGATCATCAACAAAATCAACGAC 2.

$\mathrm{V}$

1. GGCT ACCTGACCGGCATGGGCGTTACCGCCATCTGGATCTCCCAGCCGGTCGAGAACATCTACAGCGTCATCAATTATTCCGGCGTGAAT 2. $-\mathrm{T}-\mathrm{TT}-\mathrm{T}$

360

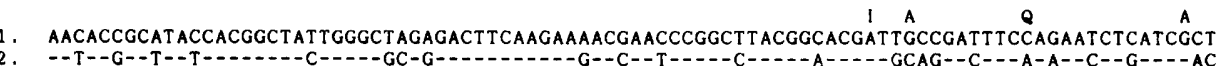

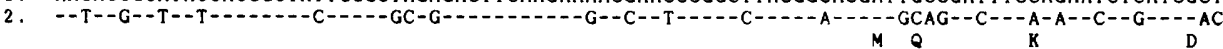

A K $\quad$ K

1. GCCGCCCATGCCAAGAACATCAAAGTCATCATCGACT TCGCACCGAACCACACGTCTCCCGCTTCCTTGGACCAGCCGTCGTTTGCGGAG A$N$ N D E $\mathrm{H}$ N

1. AACGGCAAGCTGTACAACAACGGCAGGGACGAAGGCGGATACACGAACGATACGCACAATTTATTCCATCATAACGGGGGCACCGATTTT

2. $R \quad R \quad R L L C$ $T$ $\tau$

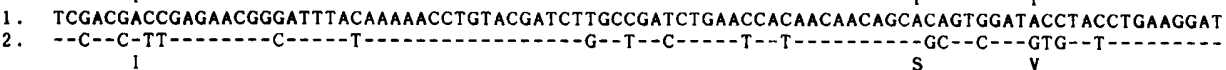
I 1 M Nde I

1. GCCATTAAAATGTGGCTCGATCTGGGCATTGACGGCATTCGAATGGACGCGGTAAAACATATGCCGTTCGGCTGGCAGAAGAGCTTCATG 2. $\begin{array}{llllll}\mathbf{V} & \mathrm{T} & \mathbf{V} & \mathrm{A} & \mathrm{N} & \mathbf{K}\end{array}$

1. GCCACCGTCAACAATTACAAGCCGGTCTTCACCTTCGGCGAATGGTTCCTCGGGGTAAACGAAGTGAGTGCCGAGAATCATAAGTTCGCC TV $\quad R \quad$ T

1. AACGTTTCCGGCATGAGCCTGCTGGACTTCCGCTTCGCGCAGAAGGTTCGCCAGGTATTCAAGGACAACACCGACAATATGTACGGACTO 1. AACGTTTCCGGCATGAGCCTGCTGGACTTCCGCTTCGCGCAGAAGGTTCGCCAGGTATTCAAGGACAACACCGACAATATGTACGGACTG
2.
E

S A T M E

1. AAATCCATGCTAGAGgGCTCTGCGACCGATTACGCGCAGATGGAGGATCAGGTCACGTTCATCGATAACCACGACATGGAACGTTTCCAC 2. A E $\mathrm{V}$

N N S A N

1. AATAACAGCGCCAACCGCCGGAAGCTGGAGCAAGCGCTCGCCTTCACGTTAACTTCCCGCGGCGTGCCAGCCATCTATTATGGAACCGAG - CC-G--AT-G-G--A-A-1 G G D $\mathbf{S} \mathbf{k}$

1. CAATACATGTCCGGCGGGAACGATCCCGACAACCGGGCTCGAATTCCTTCTTTCTCTACCACGACTACGGCTTATCAGGTCAGTAAAAAG

2. --G--T--- -T-I $Q$

1. CTGGCGCCTCTGCGTAAATCCAATCCGGCCATCGCTTATGGGACGACGCAGGAGCGCTGGaTAAACAACGATGTGTTGATCTATGAGCGC

2. --C--T--G--C--C--- - - C-

\section{V}

$\checkmark \quad S$

1. AAGTTCGGCAACAACGTAGCCGTCATCGCCGTCAACCGCAACGTGAACACGTCGGCCTCCATTACGGGACTGGTAACCTCACTGCCGGCC

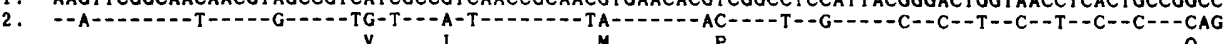

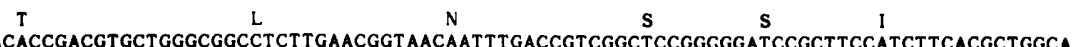

1. GGCAGCTACACCGACGTGCTGGGCGGCCTCTTGAACGGTAACAATTTGACCGTCGGCTCCGGCGGATCCGCTTCCATCTTCACGCTGGCA 1530

2.

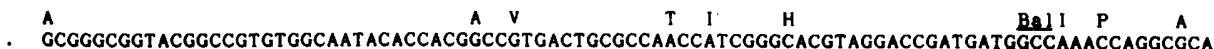
1. GCGGGCGGTACGGCCGTGTGGCAATACACCACGGCCGTGACTGCGCCAACCATCGGGCACGTAGGACCGATGATGGCGAAACCAGGCGCA
2. C-T- 200
P 


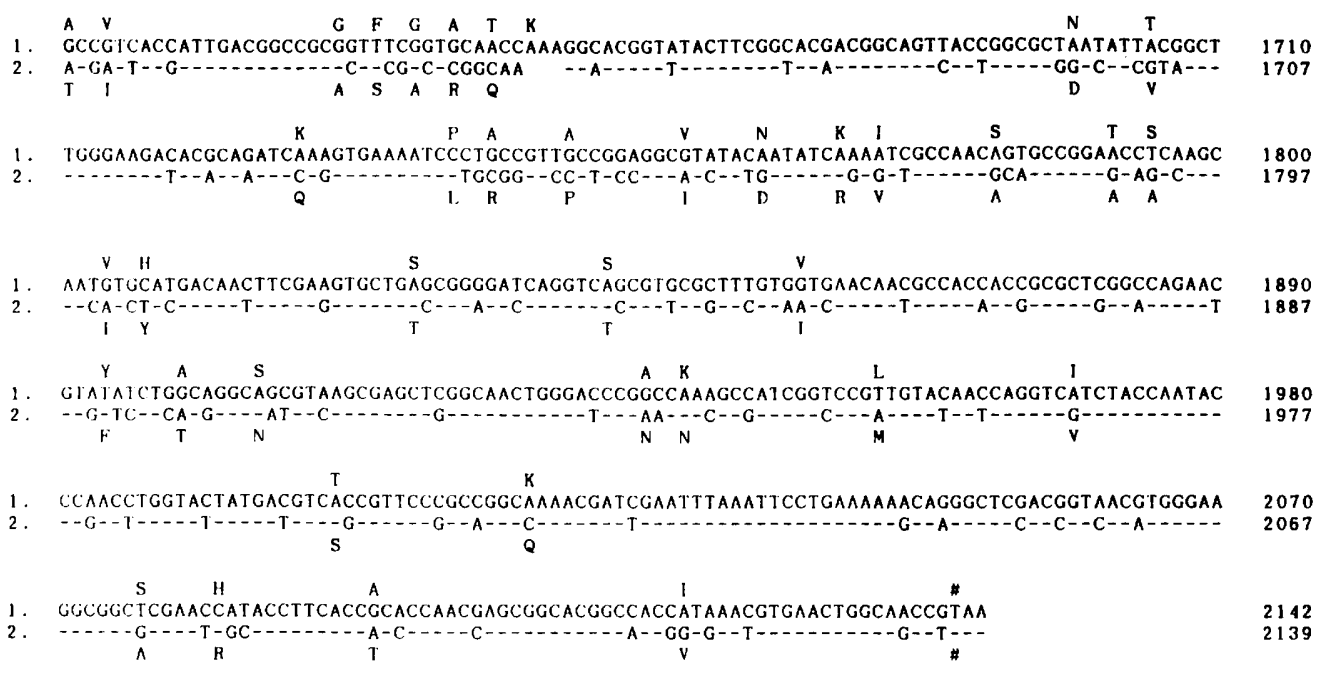

Fig. 4. Comparison of the nucleotide sequence and the deduced amino acid sequence of the CGTase 17-1 gene (1) and the CGTase 38-2 gene (2). Dashes represent identical nucleotides. The deduced amino acids that are different are indicated below and above the nucleotide sequence. The nucleotides are numbered taking initiation $A$ as 1 . The position of processing of the signal peptide is indicated by an arrow.

Table 2. Comparison of CGTase 17-1 and CGTase 38-2

CGTase 17-1

Amino acid residues
(Signal peptide)
$M_{\mathrm{r}}$ of mature enzyme
Homology
$\quad$ Nucleotide
Amino acid
Heat stability*
pH-activity profile
Optimum pH

713

74140

$\begin{array}{ccc} & 77 \% & \\ 53{ }^{\circ} \mathrm{C} & 83 \% & \\ \text { narrow } & & 65^{\circ} \mathrm{C} \\ 6 & & \text { broad } \\ 6,9\end{array}$

CGTase 38-2

712

75160

$65^{\circ} \mathrm{C}$

broad

* Temperature at which $50 \%$ loss of activity occurred (see Fig. 7 and text).

CGTase 38-2 genes. In the amino acid sequences, $593(83 \%)$ of the aligned amino acids were identical. The overall homology of the aligned nucleotide sequence was $77 \%$. However, the enzymic features, especially the heat stability and optimum pH, of the two CGTases were distinct (Table 2). To analyse these differences further, we constructed chimeric CGTases using the two genes and compared their enzymic properties.

\section{Construction and comparison of chimeric CGTases}

Construction of chimeric CGTases. As described in Methods, 12 chimeric CGTase genes were constructed (Fig. 5). Schematic representations of the chimeric CGTases are shown in Fig. 6. $E$. coli $\mathrm{HB} 101$ cells harbouring the various chimeric genes were grown aerobically in $10 \mathrm{ml} \mathrm{LB}$ broth for $24 \mathrm{~h}$ at $37^{\circ} \mathrm{C}$, then harvested and sonicated. The lysates were dialysed against running tap water and these crude extracts were used as the enzyme preparations. Their activities were 270-440 units per $\mathrm{ml}$ broth; $E$. coli harbouring pUC19 had no dextrinizing activity. SDSpolyacrylamide gel electrophoresis and Western blot analysis indicated that the 14 enzyme proteins (CGTase 17-1, CGTase 38-2 and 12 chimeric CGTases) had almost the same $M_{\mathrm{r}}$ as expected. 


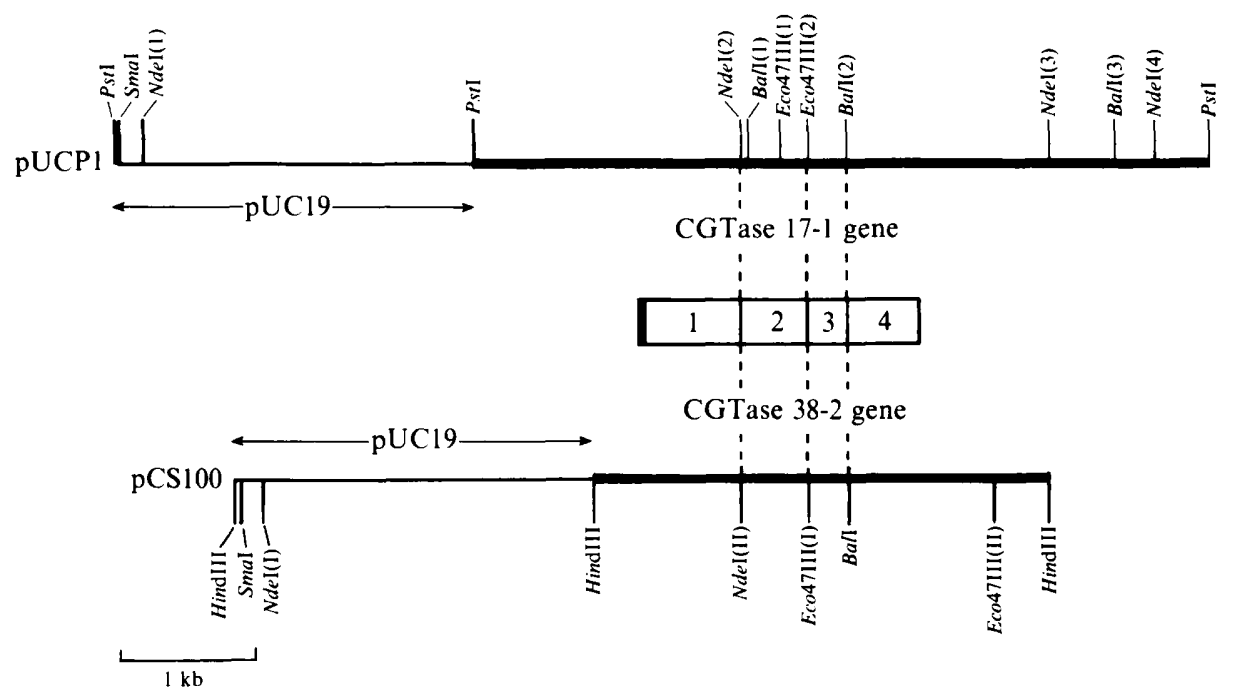

Fig. 5. Construction of chimeric CGTases. Restriction endonuclease sites which were used for construction of chimeric CGTases are indicated. The thick lines indicate the fragments containing the CGTase genes from alkalophilic Bacillus, and thin lines indicate the vector plasmid pUC19.

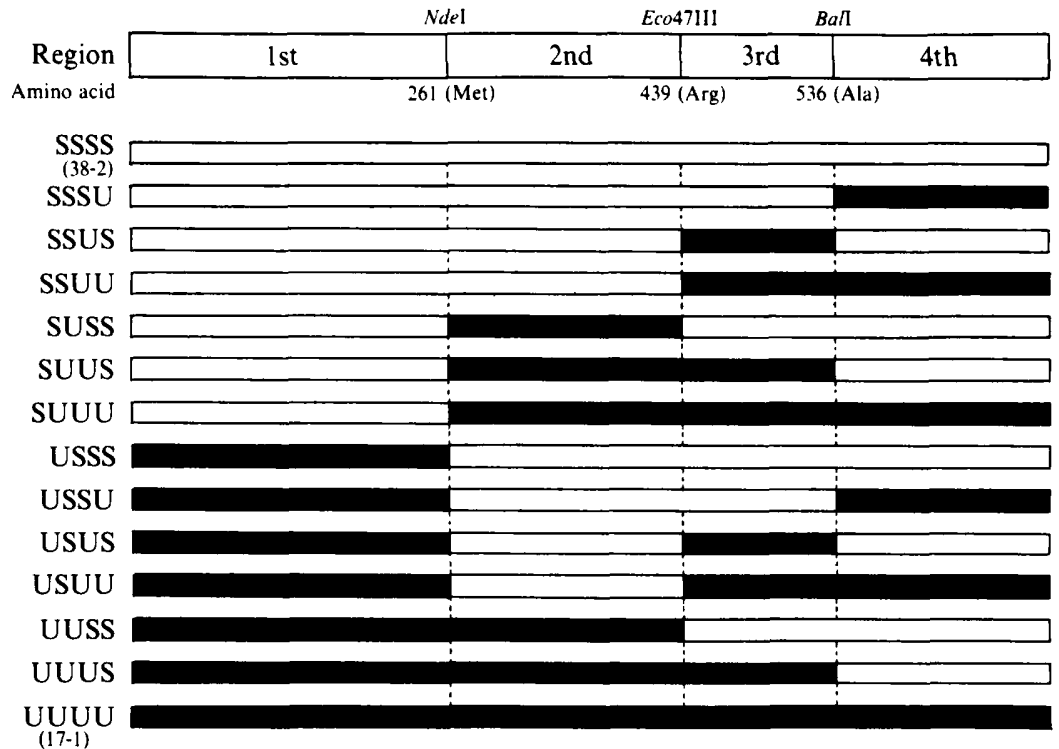

Fig. 6. Schematic representation of chimeric CGTase genes. The restriction endonuclease sites used were $N d e I, E c o 47 I I I$ and $B a I$, and their amino acid residues were numbered taking initiation Met as 1 . 'S' and open boxes represent regions from CGTase 38-2; ' $U$ ' and filled boxes represent regions from CGTase 17-1.

Heat stability of chimeric CGTases. With respect to the heat stability of the chimeric CGTases, their N-terminal segment was most important. As shown in Fig. 7, among the 14 CGTases, those enzymes ( $\mathrm{S}---$ ) which contained the $\mathrm{N}$-terminal segment derived from CGTase 38-2 were more stable than those (U--) which contained the $\mathrm{N}$-terminal segment derived from CGTase 17-1 ('S' and ' $U$ ' represent regions from CGTase 38-2 and CGTase 17-1, respectively). The second segment also had some role in increasing heat stability. Among the enzymes (S---) 

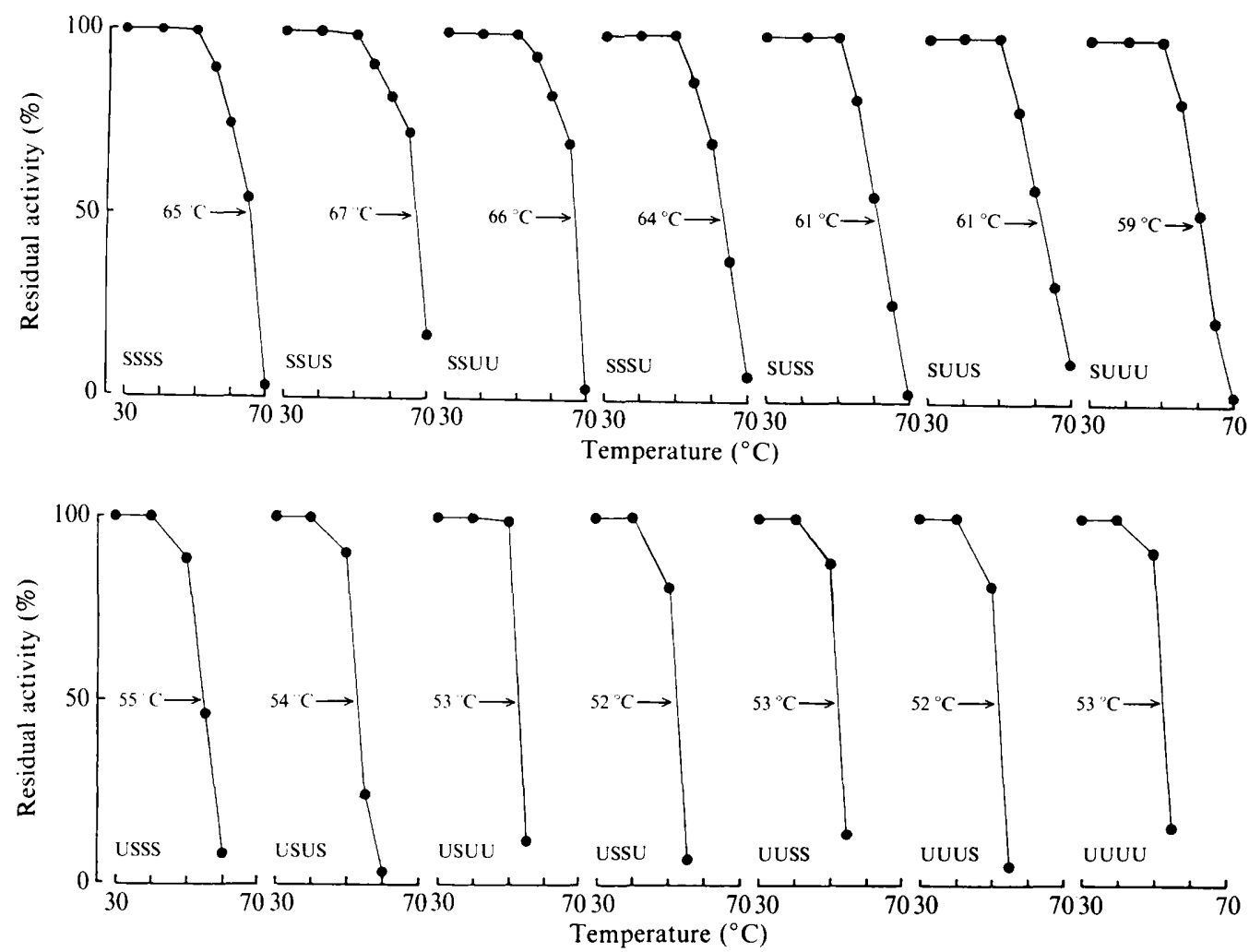

Fig. 7. Comparison of heat stability of chimeric CGTases. Each enzyme in $10 \mathrm{~mm}$-phosphate buffer (pH 6.0) was treated at $40,50,55,60,65$ and $70^{\circ} \mathrm{C}$ for $30 \mathrm{~min}$. The residual activities were measured by the standard method (see Methods). The temperatures in each figure represent the point of $50 \%$ loss of activity. ' $S$ ' and ' $U$ ' represent regions from CGTase 38-2 and CGTase 17-1, respectively (see Fig. 6).

whose first (N-terminal) segment was from CGTase 38-2, those chimeric CGTases (SS--) which contained a second segment from CGTase 38-2 were most stable. The third and the fourth segment apparently did not contribute to heat stability.

The homologies of the first, second, third and fourth segments were $86.1 \%, 86.0 \%, 81.4 \%$ and $77.7 \%$, respectively. It is interesting that the heat stability was changed distinctly by substituting the two most homologous segments, the first and second segments. Thus, heat stability may be influenced by only a few amino acid substitutions. Several properties are known to influence the heat stability of proteins. Insertions of helix-breaking amino acids (proline, threonine, etc.) into an alpha-helix decreases heat stability, and insertion of helix-forming amino acids (glutamic acid, alanine, etc.) into an alpha-helix increases heat stability. The secondary structures of the two CGTases were predicted by Chou-Fasman's method and the numbers of helix-forming and helix-breaking amino acid residues in the alpha-helix regions were compared. There were fewer helix-breaking and more helix-forming amino acid residues in the alpha-helix region of CGTase 17-1 than those of CGTase 38-2, suggesting that the number of helix-breaking and helix-forming amino acids may not be the primary influence on heat stability of the CGTases. Hydrophobic interaction inside the protein molecule is also important in stabilizing protein structure. Comparing the first and second segments of CGTase 38-2 and CGTase 17-1, amino acid substitution from CGTase 17-1 to CGTase 38-2 increased its hydrophobic properties a little. These substitutions might be important for heat stability. 

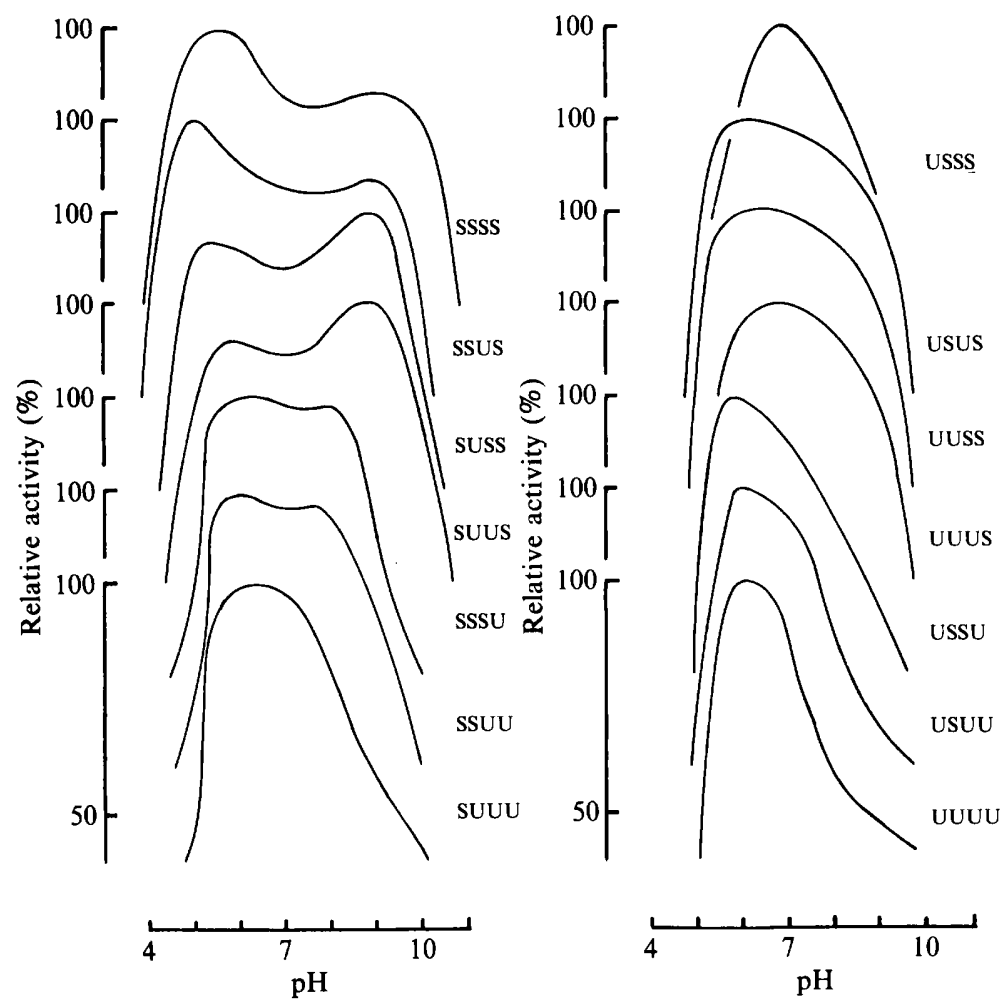

Fig. 8. Comparison of $\mathrm{pH}$-activity profiles of chimeric CGTases. The $\mathrm{pH}$ was adjusted with the

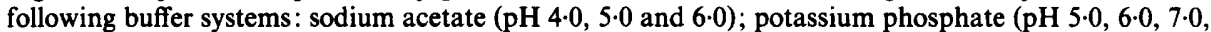

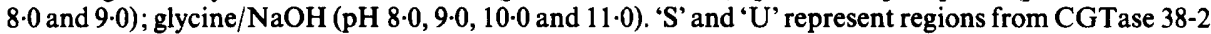
and CGTase 17-1, respectively (see Fig. 6).

pH-activity profiles of chimeric CGTases. The $\mathrm{pH}$-activity profile depended on both the $\mathrm{N}$ terminal and C-terminal segments. As shown in Fig. 8, the chimeric CGTases ( $\mathrm{S}--\mathrm{S})$ which contained the $\mathrm{N}$ - and $\mathrm{C}$-terminal segments derived from CGTase 38-2 showed two $\mathrm{pH}$ optima, at pH 6 and pH 9, and those enzymes ( $\mathrm{U}--\mathrm{U}$ ) which contained the $\mathrm{N}$ - and $\mathrm{C}$-terminal segments from CGTase 17-1 showed only one $\mathrm{pH}$ optimum, at $\mathrm{pH}$ 6. Those chimeric enzymes which contained the $\mathrm{N}$-terminal segment from CGTase 38-2 and the C-terminal segment from CGTase 17-1 (S--U), or which contained the N-terminal segment from CGTase 17-1 and the C-terminal segment from CGTase 38-2(U--S), showed intermediate $\mathrm{pH}$ profiles. There was no change of $\mathrm{pH}$ profile upon substitution of the third segment except with the chimeric enzymes USSS and USUS.

Yamane et al. (1984) reported that the $\alpha$-amylase produced by $B$. natto (B. subtilis) IAM 1212 had a deletion of about 100 amino acid residues near the $C$-terminal region, but this deletion did not affect enzyme activity. Fukumori et al. (1987) reported that the cellulase of alkalophilic Bacillus sp. no. 1139 had a size of $92 \mathrm{kDa}$ and that the large C-terminal part (about $46 \mathrm{kDa}$ ) of the cellulase was not necessary for enzyme activity. In contrast, the CGTases studied here consisted of about 720 amino acid residues, and in our unpublished findings CGTases lacking 30 amino acid residues from the $\mathrm{C}$-terminal end showed no enzyme activity. These results suggest that the C-terminal part of the enzyme is important for CGTase activity. The change of $\mathrm{pH}-$ activity profile on substitution of the C-terminal segment might be related to this phenomenon.

Our analysis of the chimeric CGTases suggests that the $\mathrm{N}$ - and/or C-terminal segment(s) might be important for the CGTase specificity. The third segment might not be essential for the enzyme specificity. 
We would like to thank Mr Weyne Bellamy for his critical reading of this manuscript.

This research was partially supported by Grants from Life Science Promotion, The Riken Institute and from the Ministry of Education, Science, and Culture of Japan.

\section{REFERENCES}

Bolivar, E., Rodriguez, R. L., Greene, P. J., Betlach, M. C., Heynecker, H. L. \& Boyer, H. W. (1977). Construction and characterization of new cloning vehicles. II. A multi-purpose cloning system. Gene 2, 95-113.

Davis, R. W., Botstein, D. \& Roth, J. R. (1980). Advanced bacterial genetics. In $A$ Manual for Genetic Engineering. pp. 120-121. Cold Spring Harbor, NY: Cold Spring Harbor Laboratory.

Edman, P. \& Henschen, A. (1975). Sequence determination. In Protein Sequence Determination, 2nd edn, pp. 232-279. Edited by S. B. Needleman. Berlin: Springer Verlag.

Fukumori, F., Kudo, T. \& Horikoshi, K. (1987). Truncation analysis of an alkaline cellulase from an alkalophilic Bacillus species. FEMS Microbiology Letters 40, 311-314.

Fuwa, H. (1954). A new method for microdetermination of amylase activity by the use of amylose as the substrate. Journal of Biochemistry 41, 583-603.

Henikoff, S. (1984). Unidirectional digestion with exonuclease III creates targeted breakpoints for DNA sequencing. Gene 28, 351-359.

Kaneko, T., Hamamoto, T. \& Horikoshi, K. (1988). Molecular cloning and nucleotide sequence of the cyclomaltodextrin glucanotransferase gene from the alkalophilic Bacillus sp. strain no. 38-2. Journal of General Microbiology 134, 97-105.

Kobayashi, S., Shibuya, N., Young, B. M. \& French, D. (1984). The preparation of 6- $O$-alpha-glucopyranosyl-cyclohexaamylose. Carbohydrate Research 126, 215-224.

LANGer, P. R., WALdRoP, A. A. \& WARD, D. C. (1981). Enzymatic synthesis of biotin-labeled polynucleotides: novel nucleic acid affinity probes. Proceedings of the National Academy of Sciences of the United States of America 78, 6633-6637.

LEDERBERG, E. M. \& COHEN, S. N. (1974). Transformation of Salmonella typhimurium by plasmid deoxyribonucleic acid. Journal of Bacteriology 119, 1072-1074.

Maniatis, T., Fritsch, E. F. \& Sambrook, J. (1982).
Molecular Cloning : a Laboratory Manual, pp. 68-69. Cold Spring Harbor, NY: Cold Spring Harbor Laboratory.

Messing, J., Crea, R. \& Seeburg, P. H. (1981). A system for shotgun DNA sequencing. Nucleic Acids Research 9, 309-321.

MoOre, S. \& SteIN, W. H. (1963). Chromatographic determination of amino acids by the use of automatic recording equipment. Methods in Enzymology 6, 819-831.

Murray, C. L. \& Rabinowitz, J. C. (1982). Nucleotide sequences of transcription and translation regions in Bacillus phage 29 early genes. Journal of Biological Chemistry 257, 1053-1062.

Nakamura, N. \& Horikoshi, K. (1976). Purification and properties of neutral-cyclodextrin glycosyltransferase of an alkalophilic Bacillus sp. Agricultural and Biological Chemistry 40, 1785-1791.

SaITo, H. \& MiURA, K. (1963). Preparation of transforming DNA by phenol treatment. Biochimica et biophysica acta 72, 619-629.

Sanger, F., Nicklen, S. \& Coulson, A. R. (1977). DNA sequencing with chain-terminating inhibitors. Proceedings of the National Academy of Sciences of the United States of America 74, 5463-5467.

SoutherN, E. M. (1975). Detection of specific sequences among DNA fragments separated by gel electrophoresis. Journal of Molecular Biology 98, 503-517.

Spackman, D. H., Stein, W. H. \& Moore, S. (1958). Automatic recording apparatus for use in the chromatography of amino acids. Analytical Chemistry 30, 1190-1206.

YAMAMOTO, M., TANAKA, Y. \& HoRIKOSHI, K. (1972). Alkaline amylases of alkalophilic bacteria. Agricultural and Biological Chemistry 36, 1819-1823.

Yamane, K., Hirata, Y., Furusato, T., Yamazaki, H. \& NAKAYAMA, A. (1984). Changes in the properties and molecular weights of Bacillus subtilis M-type and $\mathrm{N}$-type alpha-amylases resulting from a spontaneous deletion. Journal of Biochemistry 96, 1849-1858. 